\title{
Desain Display Merchandise Idol Group Korea Twice
}

\author{
Ahmad Nur Rizky Firmansyah ${ }^{1 *}$, Ningroom Adiani ${ }^{2}$ \\ ${ }^{1,2}$ Jurusan Desain, Institut Teknologi Adhi Tama Surabaya, Surabaya, Indonesia
}

\begin{abstract}
The development of South Korean culture is currently very popular among teenagers, women or men. K-Pop Group Twice is one of the results of South Korean culture. Twice Group K-Pop fans also want to have idol-themed goods. Every collection owned by collectors is always exhibited or sold at local Twice Group K-Pop events. At the event, displays are used for promotional media for collection products to be sold. Based on this, facilities are needed to facilitate collectors in product promotion media in the form of booths or display collections of products that can be used during events.

The research method used to find data, used a mix of qualitative and quantitative methods, namely observing in various places related to display design, and conducting interviews with several members of the k-pop idol group community and collectors. In analyzing the design analysis used, the order of analysis is as follows: needs analysis, space analysis, display analysis, ergonomics analysis, anthropometric analysis, arrangement analysis, placement analysis, shape analysis, color analysis, system analysis, material analysis, and finishing analysis. which is on the display design for the placement of the collector's merchandise collection.

The results of the analysis show that the product has an elegant design concept and displays the shape of the characteristics that the k-pop idol Twice always brings. This display can make it easier for visitors when they want to find a collection of merchandise at events and the display can also be used at home as a placement for other collectors' collections.
\end{abstract}

Keywords: Display Design, K-pop Twice, Merchandise

\begin{abstract}
Abstrak
Perkembangan budaya Korea Selatan saat ini sangat populer dikalangan remaja, perempuan ataupun pria. K-Pop Grup Twice merupakan alah satu hasil budaya Korea Selatan. Penggemar K-Pop Grup Twice juga ingin memiliki goods atau barang yang bertema idolnya.Setiap koleksi yang dimiliki kolektor selalu dipamerkan atau dijual di event lokalK-Pop Grup Twice. Di event tersebut display digunakan untuk media promosi produk koleksi yang akan dijual.Berdasarkan hal tersebut maka dibutuhkan fasilitas untuk mempermudah kolektor dalam media promosi produk berupa booth atau display produk koleksi yang dapat digunakan saat event.

Metode penelitian dalam mencari data, digunakan mix method kualitatif dan kuantitatif yaitu dimana mengobservasi diberbagai tempat dimana yang berhubungan dengan desain display, dan melakukan wawancara dengan beberapa anggota komunitas idol group k-pop dan kolektor. Dalam menganalisis digunakanan analisis desain, dengan urutan analisis sebagai berikut: analisis kebutuhan, analisis ruang, analisis display, analisis ergonomi, analisis antropometri, analisis penataan, analisis penempatan, analisis bentuk, analisis warna, analisis sistem, analisis material, dan analisis finishing. yang ada pada desain display untuk penempatan koleksi merchandise kolektor tersebut.

Didapatkan hasil analisis, produk dengan konsep desain elegan dan menampilkan bentuk dari ciri khas yang selalu dibawakan oleh idola k-pop Twice. Display ini dapat untuk mempermudah pengunjung ketika ingin mencari koleksi merchandise di event dan display dapat juga digunakan di rumah sebagai penempatan koleksi kolektor yang lainnya.
\end{abstract}

Kata Kunci: Desain Display, K-pop Twice, Merchandise

\section{Pendahuluan}

[1] Perkembangan budaya Korea saat ini sangat populer dikalangan remaja dan dewasa baik perempuan maupun pria usiabelasan tahun hingga tiga puluhan tahun. Industri musik Korea mampu memasuki pasar musik dunia,

\footnotetext{
* Corresponding author :firmandoqq@gmail.com
} 
maka dari itu budaya K-pop tak hanya dikenal secara lokal tetapi sudah secara global dan tak sedikit pula penggemar K-pop yang ingin memiliki goods/barang yang berbau idol K-pop. Setiap koleksi yang dimiliki kolektor selalu dipamerkan atau dijual di event lokal kpop Surabaya. Event lokal yang sering dikunjungi kolektor biasanya berada di cafe dan di pusat pembelanjaan modern. Beberapa media perantara yang dapat digunakan sebagai sarana untuk mempromosikan produk antara lain adalah media elektronik ataupun media cetak. Pada saat berlangsungnya event, kolektor biasa membawa merchandise seperti light stick, slogan, photocard, album, dan poster dan kolektor memerlukan booth atau display yang digunakan untuk media promosi produk koleksi yang akan dijual. Namun tidak sedikit juga para kolektor yang tidak menggunakan booth atau display pada saat berlangsungnya event, kolektor biasa menggunakan meja dan kursi yang berada di cafe atau pusat pembelanjaan modern tersebut. Sehingga kolektor hanya dapat membawa sedikit koleksinya yang akan dipromosikan kepada pengunjung yang berada dievent.

\section{Tujuan Perancangan}

Tujuan dari perancangan produk ini, antara lain: a) Mendesain booth untuk kolektor merchandise K-Pop yang dapat digunakan saat event maupun tempat koleksi didalam rumah, b) Dapat mengetahui kebutuhan kolektor merchandise idol group Korea dalam menonjolkan hobinya.

\section{Metode Perancangan}

Metode pengumpulan data yang dilakukan peneliti adalah mix method [2] menurut Creswell, 2010: 5 yaitu suatu langkah penelitian dengan menggabungkan dua bentuk pendekatan dalam penelitian, yaitu kualitatif dan kuantitatif, metode kualitatif yang didukung dengan data kuantitatif. Metode penelitian kualitatif dilakukan dengan wawancara secara intensif. Peneliti ikut berpartisipasi dilapangan, melakukan studi aktivitas dengan kolektor-kolektor merchandise K-Pop, mencatat secara hati-hati, melakukan reflektif terhadap berbagai dokumen yang ditemukan dilapangan dan membuat laporan penelitian secara mendetail. Data kuantitatif didapatkan dari hasil kuesioner, mulai dari kuisioner pemilihan idol K-Pop yang digemari hingga kuisioner pemilihan final desain dan akan menjadi data pendukung dalam penelitian.

\section{Pembahasan}

\subsection{Studi Kasus}

Studi kasus dilakukan oleh peneliti yaitudi komunitas Kpop Surabaya tepatnya dengan gathering komunitas "Once Jawa Timur" di sesame coffee surabaya, event KPop Fever di tampan cafe surabaya dan ditempat salah satu kolektor tepatnya di perumahan pondok sedati asri sidoarjo.

\subsection{Analisa Kebutuhan}

Analisis kebutuhan merupakan analisis yang peneliti gunakan untuk mengetahui kebutuhan yang diperlukan fans idol group Twice setelah melakukan wawancara di lokasi studi kasus, antara lain Album idol group, poster, photo card, light stick dan juga slogan.

\begin{tabular}{clccccc}
\hline No & Nama & Album & PC & Poster & LS & Slogan \\
\hline 1 & Elmo & 18 & 49 & 12 & - & - \\
\hline 2 & Naekum & 8 & 53 & 16 & 1 & 3 \\
\hline 3 & Vira & 3 & 9 & 3 & 1 & 3 \\
\hline 4 & Dave & 4 & 7 & 2 & 1 & 2 \\
\hline 5 & Monic & 8 & 19 & 15 & 2 & 1 \\
\hline 6 & Risko & 4 & 20 & 3 & - & - \\
\hline 7 & Rangga & 5 & 25 & 5 & 1 & 2 \\
\hline 8 & Albert & 3 & 15 & 2 & - & - \\
\hline 9 & Putri & 4 & 8 & 1 & - & - \\
\hline 10 & Baihaqi & 3 & 15 & 2 & - & - \\
\hline \multicolumn{7}{c}{ Tabel 1 Merchandise Kolektor } \\
& Sumber : Dokumen Pribadi & &
\end{tabular}




\subsection{Analisa Ruang}

Analisis ruang merupakan analisis yang peneliti gunakan untuk mengetahui kapasitas ruang yang dibutuhkan untuk display penempatan merchandise idol group korea, dalam analisis ini peneliti melakukan wawancara terlebih dahulu kepada para fans idol group korea yang menunjukan bahwa dalam display merchandise membutuhkan 5 ruang dengan ukuran sesaui dengan jenis merchandise.

\section{Slot Ruang Album}

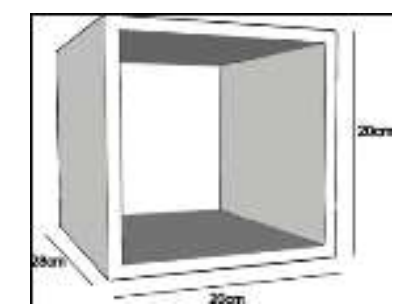

Gambar 1 Ukuran Ruang Album

Sumber : Dokumen Pribadi

Gambar diatas merupakan ukuran Slot ruang minimal yang diperlukan untuk merchandise album, yang memiliki panjang $20 \mathrm{~cm}$, lebar $28 \mathrm{~cm}$, dan tinggi $20 \mathrm{~cm}$.

\section{Slot Ruang Photocard}

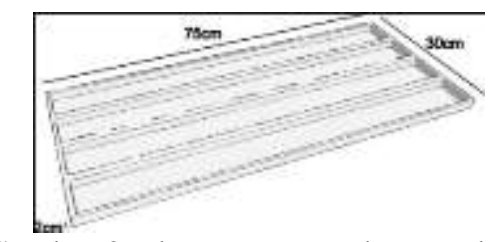

Gambar 2 Ukuran Ruang Photocard Sumber : Dokumen Pribadi

Gambar diatas merupakan ukuran slot ruang minimal yang diperlukan untuk merchandise photocard, yang memiliki panjang $75 \mathrm{~cm}$, lebar $30 \mathrm{~cm}$, dan tinggi $2 \mathrm{~cm}$

\section{Slot Ruang Poster}

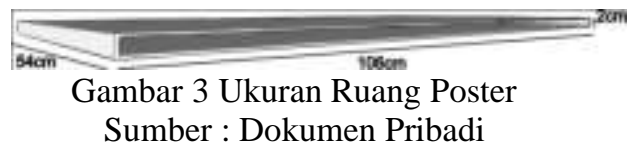

Gambar diatas merupakan ukuran slot ruang minimal yang diperlukan untuk penempatan merchandise poster, yang memiliki panjang $106 \mathrm{~cm}$, lebar $54 \mathrm{~cm}$, dan tinggi $2 \mathrm{~cm}$.

\section{Slot Ruang Lightstick}

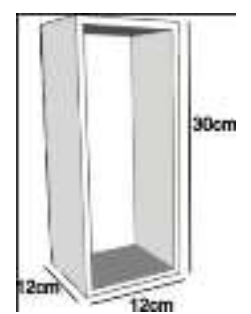

Gambar 4 Ukuran Ruang Lightstick

Sumber : Dokumen Pribadi

Gambar diatas merupakan ukuran ruang slot minimal yang diperlukan untuk penempatan merchandise lightstick, yang memiliki panjang $12 \mathrm{~cm}$, lebar $12 \mathrm{~cm}$, tinggi $30 \mathrm{~cm}$. 


\section{Slot Ruang Slogan}

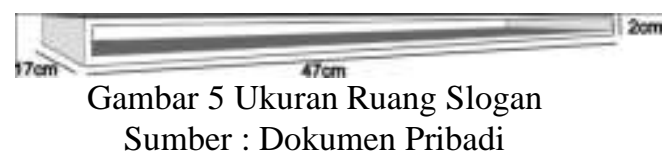

Gambar diatas merupakan ukuran ruang slot minimal yang diperlukan untuk penempatan merchandise slogan, yang memiliki panjang $47 \mathrm{~cm}$, lebar $17 \mathrm{~cm}$, tinggi $2 \mathrm{~cm}$.

\subsection{Analisa Display}

[3] Harijono dkk (2019) Banyak toko dan online shop yang baru memulai usaha maupun yang sudah lama membuka usaha sering mengikuti bazaar/pameran untuk meningkatkan pendapatan ataupun untuk memperkenalkan produk mereka. Para pengusaha dapat menyewa booth di sebuah event pameran untuk menjual barang dagangannya. Tidak sedikit dari para penyewa booth/tenant yang membawa perabot tambahan sendiri untuk mempercantik tampilan booth sekaligus,Display yang digunakan peneliti untuk display merchandise idol group Korea ditentukan dengan cara melakukan analisis dengan membandingkan beberapa jenis display antara lain Windows Display, Open Interior Display, Close Interior Display, Store Sign and Decoration, Dealer Display, Ekterior Display, dan Solari Display yang menghasilkan penggabungan antara Open Interior Display dengan Store sign and decoration.

\subsection{Analisa Antropometri}

Data antropometri adalah data-data dari hasil pengukuran yang digunakan sebagai data untuk perancangan peralatan. Mengingat bahwa keadaan dan ciri dapat membedakan satu dengan yang lainnya, maka dalam perancangan yang digunakan data antropometri terdapat tiga prinsip yang harus diperhatikan yaitu Analisis antropometri yang digunakan peneliti digunakan untuk mengetahui jarak dan ukuran yang sesuai untuk display merchandise idol group korea, yang antara lain posisi tegak yang menunjukan bahwa ukuran display maksimal $180 \mathrm{~cm}$, kemudian posisi jongkok dan duduk dengan tunggi $40 \mathrm{~cm}$ dengan jarak display dan pengguna $40 \mathrm{~cm}$, dan juga lebar display maksimal $185 \mathrm{~cm} \mathrm{[4].}$

\subsection{Analisa Sistem}

Sistem yang digunakan pada display merchandise idol group korea telebih dahulu melewat tahap analisis untuk mengetahui sistem yang sesuai dengan display merchandise idol group korea dengan mempertimbangkan kelebihan dan kekurangan dari beberapa sistem antara lain sistem Knock Down, Joining, Mobile, Built In dan juga Free Standing. Dan pada analisa sistem yang dilakukan peneliti menunjukan bahwa sistem yang digunakan Joining, Knock Down, dan Free Standing pada bagian tertentu.

\subsection{Analisa Material}

Pemilihan tema harus ditunjang dengan pemilihan furnitur dan material yang sesuai dengan tema tersebut. Material yang digunakan pada furnitur biasanya menjadi acuan pada tema yang akan diterapkan. Oleh karenanya pemilihan material perlu diperhatikan agar penggunaannya tepat dan sesuai dengan tema. Analisis material disini digunakan untuk mengetahui material yang digunakan dan cocok untuk diterapkan pada produk display yaitu kayu olahan (multiplek), kayu ini juga memiliki ketahanan dan keawetan yang kokoh dan tahan lama [5].

\subsection{Analisa Warna}

Analisis warna diterapkan pada produk display bertujuan untuk memberikan kesan khas pada koleksi merchandise tersebut dengan menggunakan analisis faktor warna dan juga arti warna menurut idol kpop yang paling banyak dipilih responden yaitu idol "Twice". 


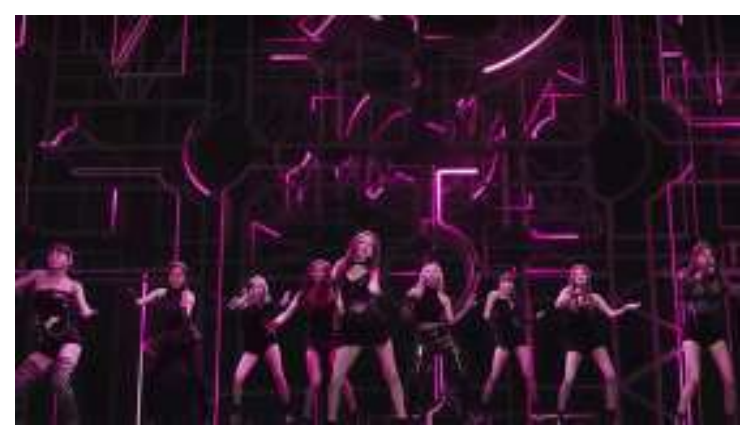

Gambar 6 Warna yang digunakan personil Twice Sumber : Dokumen Pribadi

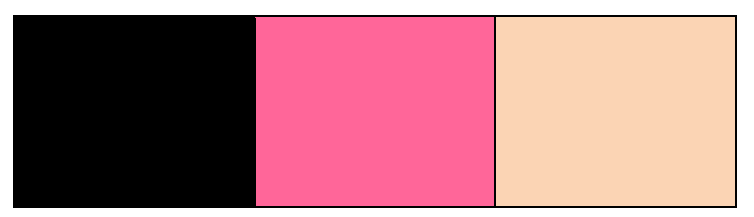

Gambar 7 Warna yang digunakan Sumber : dokumen Pribadi

Warna yang akan digunakan adalah warna hitam yang memiliki unsur elegan. Dan untuk warna aprikot dan magenta sendiri, adalah pilihan warna dari kuisioner untuk idol yang paling banyak digemari yaitu "Twice"..

\subsection{Analisa Bentuk}

Ilustrasi bentuk pohon pinus ditransformasikan dan disederhanakan menjadi rak buku dengan mekanisme knockdown [6]. Sesuai uraian diatas, maka membuat tempat display harus memiliki ciri khas grup Idol Twice. Analisa bentuk bertujuan untuk menentukan bentuk apa yang baik dan cocok digunakan untuk display merchandise idol group korea. Bentuk yang diajukan pada kuesioner untuk responden penggemar idol group korea yaitu bentuk geometris, seperti bentuk persegi panjang, belah ketupat, lingkaran, dan seterusnya. Kemudian bentuk non geometrsi dan juga bentuk logo dari idol group korea yang menunjukan ciri khas idol group tersbut .

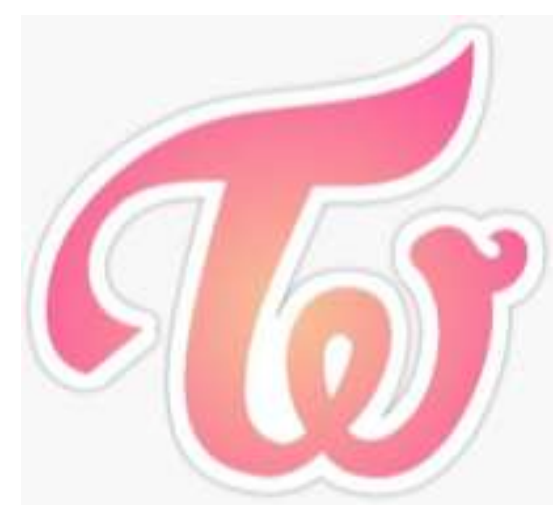

Gambar 7 Logo Idol Group Korea

Sumber : https://suratmenyurat.net/

Dan bentuk yang akan digunakan yaitu bentuk geometris dan ditambahkan dengan grafis dari ciri idol kpop yang sesuai dengan hasil kuisioner yaitu idol "Twice".

\subsection{Analisa Finishing}

Finishing yang akan di aplikasikan pada material utama display merchandice idol Kpop menggunakan cat duco, karena cat duco tersebut memiliki keunggulan dari kualitas seperti tahan lama, tahan terhadap goresan dan mudah untuk dibersihkan 


\subsection{Analisa Penempatan}

Analisis penempatan merupakan sebuah tata letak yang akan digunakan untuk koleksi merchandise idol kpop yang dimiliki kolektor berdasarkan data yang ada dilapangan, mulai dari light stick, album idol group korea, photo card, poster, hingga desain slogan dari idol group yang disukai.

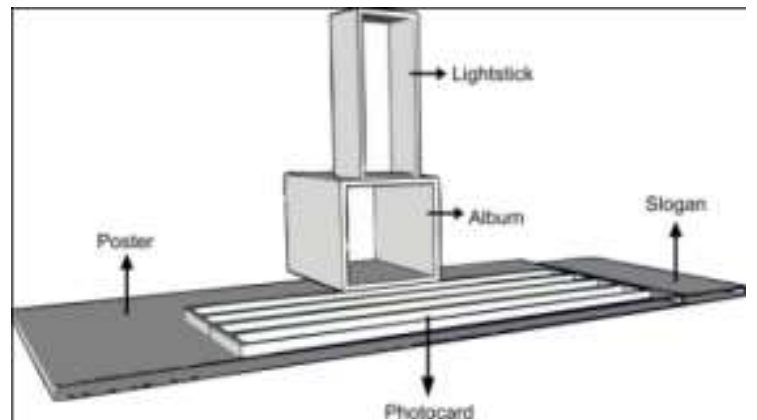

Gambar 8 Tata letak display merchandise Sumber : Dokumen Pribadi

Gambar diatas merupakan tata letak yang dari hasil analisis penempatan yang digunakan untuk koleksi merchandise idol kpop, dikarenakan slot untuk menyimpan dan menata album lebih luas sehingga dapat menaruh koleksi idol group lebih banyak.

\subsection{Sketsa Awal}

Dalam sketsa awal peneliti menerapkan bentuk persegi pada display dan terdapat logo idol "Twice" yang ditempatkan pada bagian tengah display sehingga menonjolkan cirri khas idol "Twice", dengan warna hitam yang dominan, danwarna magenta pada logo twice jugawarna apricot padatulisan "Twice".

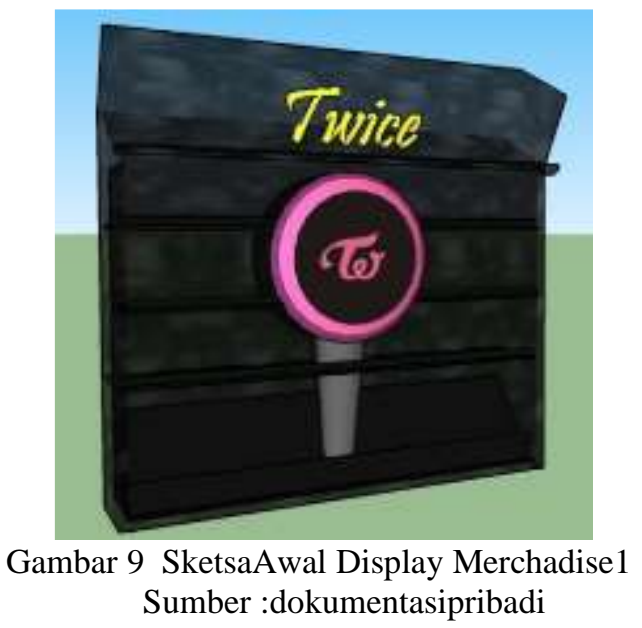

Pada sketsa kedua yaitu penerapan bentuk persegi pada display dan terdapat perubahan pada logo idol "Twice" yang ditempatkan pada bagian atas display dan diputar 90 derajat berlawanan dengan arah jam sehingga membuat ukuran display lebih tinggi. 


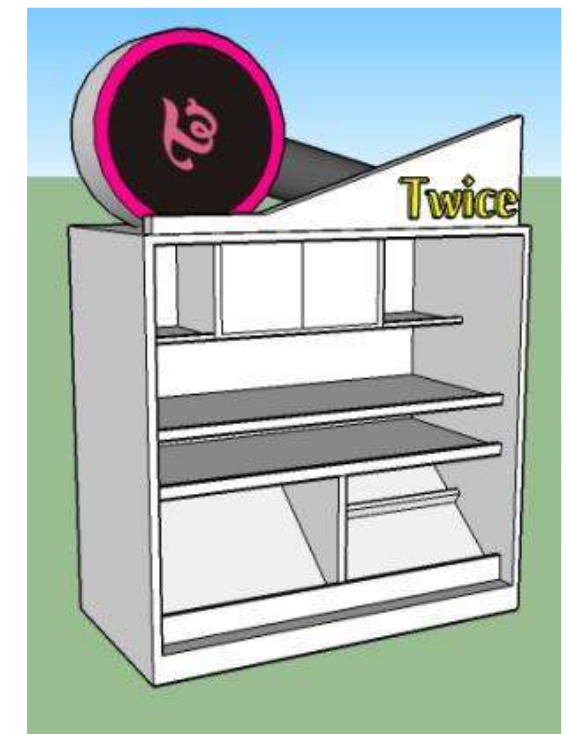

Gambar 10 SketsaAwal Display Merchadise 2 Sumber :dokumentasipribadi

\subsection{Desain Alternatif}

Pada alternatif desain pertama yaitu penerapan bentuk geometris pada display dan slot penyimpanan, terdapat logo idol "Twice" pada sisi samping display. Menggunakan warna dominan magenta, dan outline berupa hitam dan aprikot

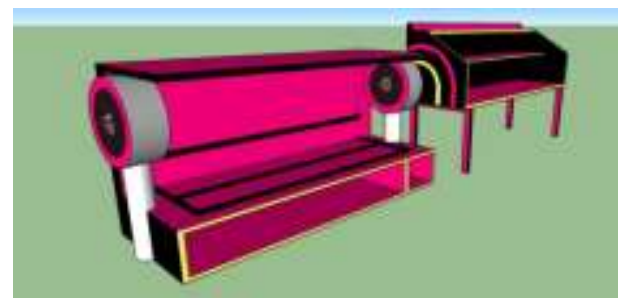

Gambar 11 DesainAlternatif Display 1 Sumber :dokumentasipribadi

Pada alternatif desain kedua yaitu penerapan bentuk geometris pada display dan slot penyimpanan, pada alternatif kedua ini dibuat lebih simple dimana hanya menerapkan bentuk persegi dan setengah lingkaran pada display dan penempatan logo idol "Twice" berada di atas dan di samping display.

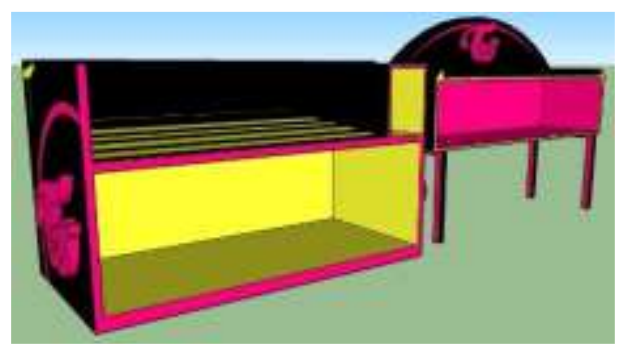

Gambar 12 Desain Alternatif Display 2

Sumber :dokumentasi pribadi

Pada alternatif desain ketiga yaitu penerapan bentuk geometris pada display dan terdapat logo idol "Twice" pada sisi samping display juga terdapat lingkaran pada sisi display dengan warna magenta. 
Ahmad Nur Rizky Firmansyah, Ningroom Adiani Desain Desplay Merchandise Idol Group Korea Twice

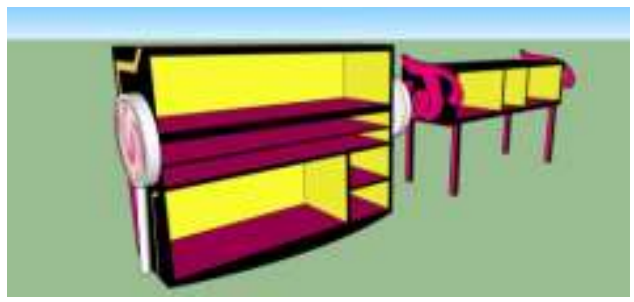

Gambar 13 DesainAlternatif Display 3 Sumber :dokumentasipribadi

\subsection{Desain Penembangan}

Pengembangan desain dilakukan dengan cara mengaplikasikan hasil kuesioner visual alternatif desain yaitu alternatif desain 3 dan alternatif desain yang dipilih oleh peneliti yaitu alternatif desain 1 .
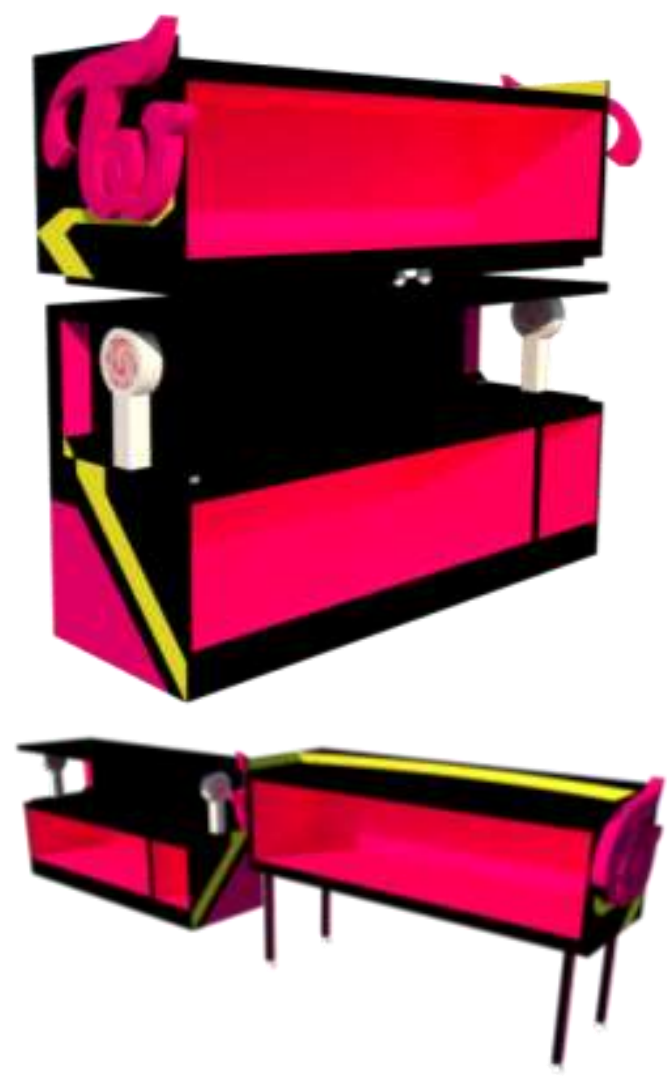

Gambar 14 Desain Pengembangan Display Sumber : Dokumentasi Pribadi

Pada desain pengembangan yaitu penerapan bentuk geometris pada display dan slot penyimpanan, pada slot bagian atas dapat digunakan saat event berlangsung kemudian terdapat logo idol "Twice" pada sisi samping display dengan warna dominan magenta dan warna apricot sebagai ornament dari display.

\section{Kesimpulan dan Saran}

\subsection{Kesimpulan}

Desain Display untuk Kolektor Merchandise Idol Group Korea Daerah Surabaya bertujuan memberikan tempat barang-barang koleksi merchandise K-Pop seperti photocard, album, lightstick, slogan dan poster. Display ini juga memiliki ukuran optimum yaitu $150 \mathrm{~cm}$ x $55 \mathrm{~cm} \times 150 \mathrm{~cm}$.

Display ini juga dapat dibawa oleh kolektor ketempat event untuk dijadikan sebuah media promosi display saat kolektor berada dievent, display tersebut memiliki ukuran sendiri yaitu $150 \mathrm{~cm}$ x $55 \mathrm{~cm}$ x $40 \mathrm{~cm}$ (tanpa kaki). Ukuran dengan menggunakan kaki display $150 \mathrm{~cm}$ x $55 \mathrm{~cm} \times 75 \mathrm{~cm}$. 


\subsection{Saran}

Penelitian Desain Display untuk Kolektor Merchandise Idol Group Korea ini masih memiliki kekurangan, dimana display yang saat digunakan dievent terlalu besar, mungkin harus dikambangkan lagi agar lebih mudah dibawa pada saat event. 
Ahmad Nur Rizky Firmansyah, Ningroom Adiani Desain Desplay Merchandise Idol Group Korea Twice

\section{Daftar pustaka}

1. Oktaviani, A., E-Commerce Merchandise Kpop Pada Toko Haruna 88 Jakarta Menggunakan Unified Modeling Language ( $U m l$ ). 2016: p. 8.

2. Aini, N.R., et al., DESAIN PENELITIAN MIXED METHOD 2020.

3. Harijono, R. and G. Mulyono, Perancangan Produk Interior Multifungsi Dan Adjustable Untuk Produk Pakaian, Sepatu Dan Tas. Intra, 2019. 7: p. 10.

4. $\quad$ Soetomo, S., Prinsip-Prinsip Perancangan Berbasiskan Dimensi Tubuh (Antropometri ). Tek Ind, 2015. 159(1): p. 11.

5. Tf, B.A. and D. Susilawati, Penggunaan Material Furnitur Sebagai Pendukung Tema Pada Desain Interior Nanny S Pavillon Di Bandung. J. Rekajiva J. Online Inst. Teknol. Nas, 2013. 1(2): p. 15.

6. $\quad$ Adiani, N., S. Pengajar, and J. Desain, Desain rak buku berbentuk pepohonan pinus dari janggel jagung dan resin polimer. 